Carmen L R Lopes ${ }^{1, I I}$

Sheila A Teles"

Márcia P Espírito-Santo

Elisabete Lampe ${ }^{\text {III }}$

Fabiana P Rodrigues ${ }^{\text {IV }}$

Ana Rita C Motta-Castrov

Thaís A Marinho'

Nádia R Reis ${ }^{1}$

Ágabo M C Silva'

Regina M B Martins'

Instituto de Patologia Tropical e Saúde Pública. Universidade Federal de Goiás (UFG). Goiânia, GO, Brasil

Faculdade de Enfermagem. UFG. Goiânia, GO, Brasil

III Instituto Oswaldo Cruz. Fundação Oswaldo Cruz. Rio de Janeiro, RJ, Brasil

$\checkmark$ Faculdade de Enfermagem. Universidade Estadual de Mato Grosso do Sul. Dourados, MS, Brasil

Departamento de Farmácia-Bioquímica. Universidade Federal de Mato Grosso do Sul. Campo Grande, MS, Brasil

Correspondência | Correspondence: Regina Maria Bringel Martins R. 235, S/N - Setor Universitário Caixa Postal 131

74605-050 Goiânia, GO, Brasil

E-mail: rbringel@terra.com.br

\section{Prevalência, fatores de risco e genótipos da hepatite $C$ entre usuários de drogas}

\section{Prevalence, risk factors and genotypes of hepatitis $C$ virus infection among drug users, Central- Western Brazil}

\section{RESUMO}

OBJETIVO: Estimar a prevalência e fatores associados à infecção pelo vírus da hepatite $\mathrm{C}$ em usuários de drogas e identificar os genótipos e subtipos virais circulantes.

MÉTODOS: Estudo realizado com 691 usuários de drogas de 26 centros de tratamento de uso de drogas filantrópicos, particulares e públicos de Goiânia (GO) e Campo Grande (MS), entre 2005 e 2006. Dados sociodemográficos e fatores de risco para infecção pelo HCV foram obtidos por meio de entrevistas. Amostras sangüíneas foram testadas para a detecção de anticorpos para o HCV. As amostras positivas foram submetidas à detecção do RNA-HCV pela reação em cadeia da polimerase com iniciadores complementares às regiões 5' NC e NS5B do genoma viral e genotipadas pelo line probe assay (LiPA) e por seqüenciamento direto, seguido de análise filogenética. Prevalência e odds ratio foram calculados com intervalo de $95 \%$ de confiança. Os fatores de risco com $\mathrm{p}<0,10$ pela análise univariada foram analisados por regressão logística hierárquica. Valores de $\mathrm{p}<0,05$ foram considerados estatisticamente significantes.

RESULTADOS: A prevalência para anti-HCV foi 6,9\% (IC 95\%: 5,2;9,2). A análise multivariada de fatores de risco indicou que idade superior a 30 anos e uso injetável de drogas se mostraram associados à infecção pelo HCV. O RNA-HCV foi detectado em 85,4\% (41/48) das amostras anti-HCV positivas. Trinta e três amostras foram do genótipo 1 pelo LiPA, subtipos 1a $(63,4 \%)$ e 1b (17,1\%), e 8 (19,5\%) do genótipo 3, subtipo 3a. A análise filogenética da região NS5B mostrou que 17 (68\%), 5 (20\%) e 3 (12\%) amostras foram dos subtipos 1a, 3a e 1b, respectivamente.

CONCLUSÕES: Os resultados mostram uma prevalência elevada da infecção e do subtipo 1a do HCV em usuários de drogas, sendo o uso injetável de drogas o principal fator de risco para essa infecção.

DESCRITORES: Hepatite C. Anticorpos Anti-Hepatite C, uso diagnóstico. Hepacivirus, genética. Abuso de Substâncias por Via Intravenosa. Uso Comum de Agulhas e Seringas. Fatores de Risco. Estudos Soroepidemiológicos. 


\section{ABSTRACT}

OBJECTIVE: To estimate prevalence of hepatitis C virus (HCV) infection and identify risk factors associated and circulating HCV genotypes and subtypes.

METHODS: Study conducted including 691 drug users attending 26 charitable, private and public drug treatment centers in Goiânia and Campo Grande, centralwestern Brazil, between 2005 and 2006. Sociodemographic characteristics and risk factors for HCV infection were collected during interviews. Blood samples were tested for HCV antibodies (anti-HCV). Positive samples were submitted to HCV RNA detection by PCR with primers complementary to 5' NC and NS5B regions of viral genome and genotyped by line probe assay (LiPA) and direct nucleotide sequencing followed by phylogenetic analysis. The prevalence and odds ratio were calculated with $95 \%$ confidence intervals. Risk factors were first estimated in the univariate analysis $(p<0.10)$ and then analyzed by hierarchical logistic regression. Statistical significance was assessed at a $5 \%$ significance level.

RESULTS: The prevalence of anti-HCV was 6.9\% (95\% CI: 5.2-9.2). The multivariate analysis of risk factors revealed that age over 30 years and injecting drug use were associated with HCV infection. HCV RNA was detected in $85.4 \%$ (41/48) of anti-HCV-positive samples. Thirty-three samples were genotyped as genotype 1 by LiPA, subtypes 1a (63.4\%) and $1 \mathrm{~b}$ (17.1\%), and 8 samples (19.5\%) were genotype 3, subtype 3a. The phylogenetic analysis of the NS5B region showed that 17 (68\%), 5 (20\%), and $3(12 \%)$ samples were subtypes 1a, 3a, and $1 \mathrm{~b}$, respectively.

CONCLUSIONS: The results show a high prevalence of HCV infection and predominance of subtype 1a among drug users in Brazil. In addition, injecting drug use was a major risk factor associated with HCV infection.

\section{DESCRIPTORS: Hepatitis C. Hepatitis C Antibodies, diagnostic use. Hepacivirus, genetics. Substance Abuse, Intravenous. Needle Sharing. Risk Factors. Seroepidemiologic Studies.}

\section{INTRODUÇÃO}

A infecção pelo vírus da hepatite C (HCV) é considerada um importante problema de saúde pública. Estima-se que cerca de 2,2\% da população mundial, o equivalente a 130 milhões de pessoas, estejam infectados por esse vírus. ${ }^{1}$ A hepatite $\mathrm{C}$ aguda geralmente se apresenta de forma assintomática. No entanto, a maioria dos casos evolui para cronicidade, podendo levar ao desenvolvimento de cirrose hepática e carcinoma hepatocelular, conferindo a essa virose importante causa de morbimortalidade. ${ }^{3}$

O genoma do HCV apresenta alto grau de variabilidade genética. Seis genótipos e múltiplos subtipos têm sido identificados, os quais apresentam diferença na resposta ao tratamento antiviral, bem como uma distribuição geográfica distinta. Os genótipos 1, 2 e 3 são amplamente disseminados em todo o mundo. O genótipo 4 é mais prevalente no norte da África e Oriente Médio. Por outro lado, infecções pelos genótipos 5 e 6 são comuns na África do Sul e Ásia, respectivamente. ${ }^{24}$ No Brasil, estudos têm mostrado o genótipo 1 como o mais prevalente, seguido pelo genótipo 3., ${ }^{5,18}$
O HCV é mais eficientemente transmitido pela via parenteral, por transfusão e/ou contato com sangue e seus produtos, mas pode também ser disseminado menos eficientemente pela via sexual e vertical. ${ }^{1}$ Assim, os usuários de drogas (UD) apresentam risco aumentado de adquirir a infecção causada por esse vírus, devido ao compartilhamento de equipamentos para uso de drogas e à adoção de práticas sexuais desprotegidas. ${ }^{12,13,16,23}$

No Brasil, ainda são poucos os estudos sobre a infecção pelo HCV em UD englobando os grupos injetáveis e não injetáveis, cujas taxas de prevalência variaram de $5,8 \%$ a $36,2 \%$. $^{2,710,19,23}$

O presente estudo é a primeira investigação sobre a infecção pelo HCV em usuários de drogas ilícitas e teve por objetivo estimar a prevalência e fatores associados à infecção por HCV em usuários de drogas. Além disso, buscou-se e identificar os genótipos e subtipos virais circulantes. 


\section{MÉTODOS}

Foi realizado um estudo transversal com amostra de conveniência em todos os centros de tratamento de uso de drogas filantrópicos, particulares e públicos de Goiânia (GO) e Campo Grande (MS), de agosto de 2005 a julho de 2006. Foi encontrado um total de 851 usuários, 542 de Goiânia, procedentes de 18 centros, cada um com dez a 70 indivíduos por centro; e 309 de Campo Grande (MS), procedentes de oito centros, variando de dez a 76 indivíduos por centro. Todos os participantes foram esclarecidos sobre os objetivos e procedimentos do estudo e convidados a participar da investigação, obedecendo aos seguintes critérios de inclusão: idade igual ou superior a 18 anos, ter usado drogas ilícitas injetáveis e/ou não injetáveis, estar vinculado a algum dos centros de tratamento de uso de drogas. Não houve recusa de participação. Foram considerados usuários de drogas injetáveis (UDI) indivíduos que referiram uso de drogas ilícitas por via endovenosa e usuários de drogas não injetáveis (UDNI) aqueles que nunca consumiram essas drogas por via endovenosa e reportaram o uso durante a vida de maconha, cocaína (em pó, merla, crack), heroína, LSD e ecstasy por outras vias (cheirar, fumar e ingerir). Dos 851 usuários, 691 (81,2\%) eram elegíveis para o estudo, sendo 102 UDI e 589 UDNI.

A partir de um questionário baseado no instrumento padronizado pela Organização Mundial de Saúde, ${ }^{8}$ todos os participantes foram entrevistados sobre características sociodemográficas (idade, sexo, estado civil, raça/etnia, escolaridade e renda familiar) e possíveis fatores de risco para infecção pelo HCV (via e tempo de uso de drogas, história de transfusão de sangue/ano da primeira transfusão e de cirurgia, tatuagem/piercing, acupuntura, uso de preservativo, número de parceiros sexuais, parceiro UDI, história de doença sexualmente transmissível [DST] e antecedente de prisão). A seguir, foram coletados $10 \mathrm{ml}$ de sangue de cada usuário e os soros estocados a $-20^{\circ} \mathrm{C}$.

Todas as amostras foram testadas para detecção de anticorpos para o vírus da hepatite C (anti-HCV, Hepanostika Ultra, Biomedical, China) por ensaio imunoenzimático (ELISA). A positividade para o marcador anti-HCV foi confirmada por immunoblot (Bioblot HCV, Biokit, Espanha).

As amostras anti-HCV positivas foram submetidas à extração de RNA, transcrição reversa e a reação em cadeia da polimerase (PCR), com iniciadores complementares à região 5' não codificante (NC) do genoma viral, conforme descrito por Ginabreda et al ${ }^{11}$ (1997). As amostras RNA-HCV positivas foram genotipadas pelo método line probe assay (LiPA - Versant HCV Genotype Assay, Innogenetics, Bélgica).
A análise filogenética da região NS5B do genoma viral foi realizada para confirmação dos genótipos e subtipos do HCV. Os cDNA obtidos anteriormente pela transcrição reversa foram amplificados pela PCR com iniciadores e nas mesmas condições descritas por Sandres-Sauné et $a^{22}$ (2003). Os produtos da PCR foram purificados empregando-se o kit QIAquick Gel Extraction (Qiagen, GmbH, Hilden, Germany) e submetidos à reação de seqüenciamento nucleotídico direto em ambas as direções usando o Kit Big Dye Terminator (version 3.1, Applied Biosystems, Foster City CA, USA), sendo analisados no seqüenciador ABI-3730 (Applied Biosystems). As seqüências obtidas com 340 nucleotídeos (da posição 8279 a 8619 do genoma viral) foram alinhadas usando o programa Clustal $\mathrm{X} .{ }^{25} \mathrm{~A}$ árvore filogenética foi construída pelo método Neighbor-Joining do programa Mega 2.1, ${ }^{14}$ de acordo com o modelo de análise Kimura-2 parâmetros. A robustez dos clusters da árvore foi avaliada pelo teste de bootstrap utilizando-se 1000 pseudo-réplicas. Os genótipos e subtipos das amostras do HCV foram determinados acrescentando-se, na análise filogenética, seqüências de referência representativas dos principais genótipos/subtipos do vírus disponíveis no Genbank (designadas na árvore filogenética pelo subtipo, seguido do número de acesso no Genbank).

A análise dos dados foi realizada utilizando-se o programa Epi Info versão 2000. Prevalência e odds ratio (OR) foram calculados com intervalo com $95 \%$ de confiança (IC 95\%). Os fatores de risco com $\mathrm{p}<0,10$ pela análise univariada foram analisados posteriormente por regressão logística hierárquica utilizando o programa SPSS versão 11.0 para identificar as possíveis variáveis confundidoras. Foram empregados os testes de $\chi^{2}$ para associação, $\chi^{2}$ para tendência e exato de Fisher. Valores de $\mathrm{p}<0,05$ foram considerados estatisticamente significantes.

O estudo foi aprovado pelo Comitê de Ética em Pesquisa do Hospital Materno Infantil (CEP-HMI n $\left.{ }^{\circ} 004 / 05\right)$, em Goiânia. Todos participantes da pesquisa assinaram Termo de Consentimento Livre e Esclarecido.

\section{RESULTADOS}

Quanto às características sociodemográficas, a média de idade da população estudada foi de 28,3 anos ( $d p=9,0)$, $88,3 \%$ eram do sexo masculino, $64,3 \%$ solteiros, $59,5 \%$ brancos, $70,2 \%$ informaram ter oito ou menos anos de escolaridade e 46,5\% relataram renda familiar entre dois e cinco salários mínimos. A maioria da população fazia uso de duas ou mais drogas não injetáveis, sendo as mais consumidas: maconha $(82,9 \%)$, cocaína na forma de pó (59,6\%), merla (52,8\%) e crack $(37,9 \%)$.

Dos 691 usuários de drogas estudados, em 49 (7,1\%) amostras foi detectado o marcador anti-HCV. Destas, 


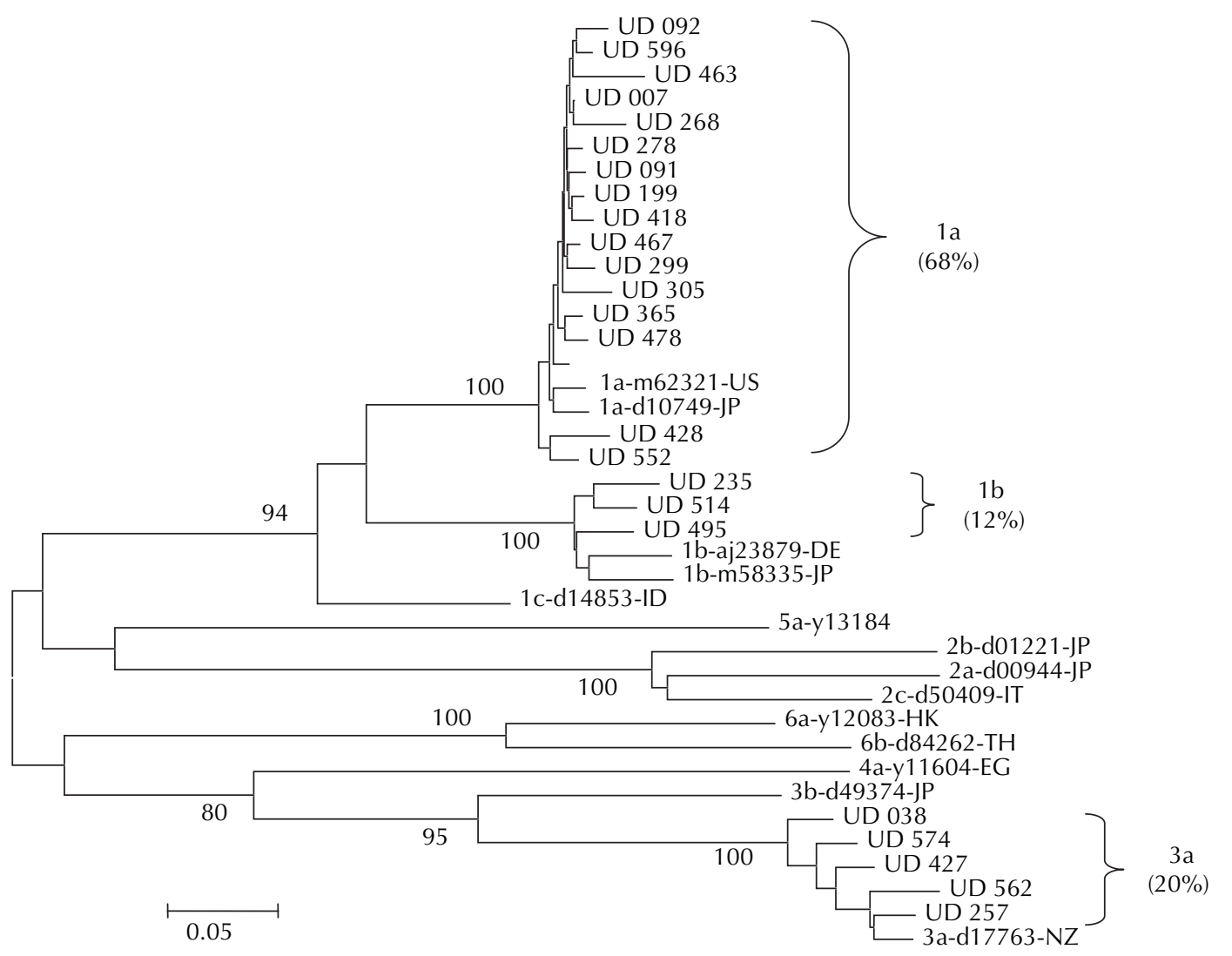

Figura. Árvore filogenética da região NS5B, incluindo isolados de usuários de drogas e seqüências do GenBank dos genótipos 1 a 6, representados pelos principais subtipos do vírus da hepatite C. Goiânia (GO) e Campo Grande (MS), 2005-2006.

48 foram positivas pelo immunoblot, resultando em uma prevalência de 6,9\% para anti-HCV (IC 95\%: 5,2;9,2) (Tabela 1).

O RNA viral foi detectado em 85,4\% (41/48) das amostras anti-HCV reagentes pela PCR com iniciadores complementares à região 5' NC, sendo todas genotipadas pelo LiPA. Trinta e três amostras foram do genótipo 1 , sendo $63,4 \%$ do subtipo 1 a e $17,1 \%$ do subtipo 1b. As demais amostras (19,5\%) foram caracterizadas como do genótipo 3, subtipo 3a (Tabela 1). Das 41 amostras RNA-HCV positivas para a região 5' NC, 25 $(60,1 \%)$ foram amplificadas e genotipadas para a região NS5B, identificando 17 (68\%) como subtipo 1a, cinco (20\%) como 3a e três (12\%) como 1b (Figura).

Pela análise univariada, a infecção pelo HCV se mostrou significativamente associada à idade, estado civil, renda familiar, via e tempo de uso de drogas, história de transfusão e de cirurgia, parceiro UDI e história de DST (Tabela 2). Após análise de regressão logística múltipla, idade superior a 30 anos $(\mathrm{OR}=16,0$; IC 95\%: 3,9;66,0) e uso de drogas injetáveis (OR=18,0; IC 95\%: 6,9;47,1) se mostraram independentemente associados à infecção pelo HCV (Tabela 3).
Tabela 1. Prevalência da infecção pelo vírus da hepatite $C$ em usuários de drogas ilícitas. Goiânia (GO) e Campo Grande (MS), 2005-2006.

\begin{tabular}{cccc}
\hline \multirow{2}{*}{ Marcador } & \multicolumn{2}{c}{ Positivo } & IC 95\% \\
& $\mathrm{n}$ & $\%$ & \\
\hline $\begin{array}{c}\text { Anti-HCV } \\
\text { ELISA }\end{array}$ & 49 & 7,1 & 5,$3 ; 9,3$ \\
$\quad \begin{array}{l}\text { Immunoblot } \\
\text { Subtipos }\end{array}$ & 48 & 6,9 & 5,$2 ; 9,2$ \\
1a & & & \\
1b & 26 & 63,4 & 46,$9 ; 77,4$ \\
3a & 7 & 17,1 & 7,$7 ; 32,6$ \\
\hline
\end{tabular}

\section{DISCUSSÃO}

O presente estudo apresenta limitações que devem ser consideradas na interpretação de seus resultados. O tamanho e as características da população de usuários de drogas em geral de Goiânia e Campo Grande não são efetivamente conhecidos, dada a dificuldade decorrente do caráter ilegal dessa atividade. Por isso investigou-se a infecção pelo HCV apenas na população de UDI e UDNI cadastrados em todos os centros de tratamento para uso de drogas filantrópicos, particulares e públicos 
Tabela 2. Fatores de risco associados à infecção pelo vírus da hepatite $\mathrm{C}$ em usuários de drogas ilícitas. Goiânia (GO) e Campo Grande (MS), 2005-2006.

\begin{tabular}{|c|c|c|c|c|}
\hline \multirow[b]{2}{*}{ Fator de risco } & \multicolumn{2}{|c|}{ Anti-HCV } & \multirow{2}{*}{$\begin{array}{c}\text { Odds } \\
\text { ratio (IC } \\
95 \%)\end{array}$} & \multirow[b]{2}{*}{$\mathrm{p}$} \\
\hline & $\begin{array}{l}\text { Positivo/ } \\
\text { Total }^{\mathbf{a}}\end{array}$ & $(\%)$ & & \\
\hline \multicolumn{5}{|l|}{ Idade (anos) } \\
\hline$\leq 30$ & $4 / 452$ & 0,9 & 1,0 & \\
\hline$>30$ & $44 / 239$ & 18,4 & $\begin{array}{c}25,3 \\
(8,9 ; 71,3)\end{array}$ & 0,000 \\
\hline \multicolumn{5}{|l|}{ Sexo } \\
\hline Feminino & $3 / 81$ & 3,7 & 1,0 & \\
\hline Masculino & $45 / 610$ & 7,4 & $\begin{array}{c}2,1 \\
(0,6 ; 6,8)\end{array}$ & 0,222 \\
\hline \multicolumn{5}{|l|}{ Estado civil } \\
\hline Solteiro & $20 / 444$ & 4,5 & 1,0 & \\
\hline Casado/amasiado & $17 / 161$ & 10,5 & $\begin{array}{c}2,5 \\
(1,2 ; 5,1)\end{array}$ & 0,012 \\
\hline Separado/viúvo & $11 / 86$ & 12,8 & $\begin{array}{c}3,1 \\
(1,3 ; 7,2)\end{array}$ & 0,000 \\
\hline \multicolumn{5}{|l|}{ Raça/Etnia } \\
\hline Branca & $34 / 411$ & 8,3 & 1,0 & \\
\hline Não branca & $14 / 280$ & 5,0 & $\begin{array}{c}0,6 \\
(0,3 ; 1,1)\end{array}$ & 0,131 \\
\hline \multicolumn{5}{|l|}{ Escolaridade (anos) } \\
\hline$\leq 8$ & $27 / 485$ & 5,6 & 1,0 & \\
\hline $9-12$ & $17 / 173$ & 9,8 & $\begin{array}{c}1,9 \\
(0,9 ; 3,6)\end{array}$ & 0,084 \\
\hline$>12$ & $4 / 33$ & 12,1 & $\begin{array}{c}2,3 \\
(0,6 ; 7,7)\end{array}$ & 0,122 \\
\hline \multicolumn{5}{|l|}{$\begin{array}{l}\text { Renda Familiar } \\
\text { (salários mínimos) }\end{array}$} \\
\hline$\leq 1$ & $16 / 282$ & 5,7 & 1,0 & \\
\hline 2 a 5 & $22 / 302$ & 7,3 & $\begin{array}{c}1,3 \\
(0,6 ; 2,7)\end{array}$ & 0,491 \\
\hline$\geq 5$ & $9 / 65$ & 13,8 & $\begin{array}{c}2,7 \\
(1,0 ; 6,8)\end{array}$ & 0,043 \\
\hline \multicolumn{5}{|l|}{ Via de uso de drogas } \\
\hline Não injetável & $16 / 589$ & 2,7 & 1,0 & \\
\hline Injetável & $32 / 102$ & 31,4 & $\begin{array}{c}16,4 \\
(8,5 ; 31,3)\end{array}$ & 0,000 \\
\hline \multicolumn{5}{|l|}{$\begin{array}{l}\text { Tempo de uso de } \\
\text { drogas (anos) }\end{array}$} \\
\hline$\leq 10$ & $5 / 330$ & 1,5 & 1,0 & \\
\hline$>10$ & $43 / 350$ & 12,3 & $\begin{array}{c}9,1 \\
(3,5 ; 23,2)\end{array}$ & 0,000 \\
\hline \multicolumn{5}{|l|}{$\begin{array}{l}\text { História de } \\
\text { transfusão }\end{array}$} \\
\hline Não & $32 / 617$ & 5,2 & 1,0 & \\
\hline Sim & $14 / 63$ & 22,2 & $\begin{array}{c}5,2 \\
(2,6 ; 10,4)\end{array}$ & 0,000 \\
\hline \multicolumn{5}{|l|}{ História de cirurgia } \\
\hline Não & $20 / 406$ & 4,9 & 1,0 & \\
\hline Sim & $27 / 283$ & 9,5 & $\begin{array}{c}2,0 \\
(1,1 ; 3,7)\end{array}$ & 0,018 \\
\hline
\end{tabular}

Continua
Tabela 2 continuação

\begin{tabular}{|c|c|c|c|c|}
\hline \multirow[b]{2}{*}{ Fator de risco } & \multicolumn{2}{|c|}{ Anti-HCV } & \multirow{2}{*}{$\begin{array}{c}\text { Odds } \\
\text { ratio (IC } \\
95 \%)\end{array}$} & \multirow[b]{2}{*}{$\mathrm{p}$} \\
\hline & $\begin{array}{l}\text { Positivo/ } \\
\text { Total }^{\mathbf{a}}\end{array}$ & $(\%)$ & & \\
\hline \multicolumn{5}{|l|}{ Tatuagem/Piercing } \\
\hline Não & $27 / 411$ & 6,6 & 1,0 & \\
\hline Sim & $21 / 280$ & 7,5 & $\begin{array}{c}1,1 \\
(0,6 ; 2,2)\end{array}$ & 0,751 \\
\hline \multicolumn{5}{|l|}{ Acupuntura } \\
\hline Não & $44 / 652$ & 6,7 & 1,0 & \\
\hline Sim & $4 / 29$ & 13,8 & $\begin{array}{c}2,2 \\
(0,7 ; 6,6)\end{array}$ & 0,280 \\
\hline \multicolumn{5}{|l|}{ Uso de preservativo } \\
\hline Regular & $8 / 145$ & 5,5 & 1,0 & \\
\hline Irregular/nunca & $40 / 546$ & 7,3 & $\begin{array}{c}1,3 \\
(0,6 ; 3,0)\end{array}$ & 0,560 \\
\hline \multicolumn{5}{|l|}{ Parceiros sexuais } \\
\hline$\leq 10$ & 18/332 & 5,3 & 1,0 & \\
\hline$>10$ & $30 / 331$ & 9,1 & $\begin{array}{c}1,7 \\
(0,9 ; 3,2)\end{array}$ & 0,070 \\
\hline \multicolumn{5}{|l|}{ Parceiro UDI } \\
\hline Não & $28 / 488$ & 5,7 & 1,0 & \\
\hline Sim & 16/101 & 15,8 & $\begin{array}{c}3,1 \\
(1,6 ; 6,0)\end{array}$ & 0,000 \\
\hline \multicolumn{5}{|l|}{ História de DST } \\
\hline Não & $18 / 459$ & 3,9 & 1,0 & \\
\hline Sim & 30/205 & 14,6 & $\begin{array}{c}4,2 \\
(2,3 ; 7,7)\end{array}$ & 0,000 \\
\hline \multicolumn{5}{|l|}{$\begin{array}{l}\text { Antecedente de } \\
\text { prisão }\end{array}$} \\
\hline Não & $12 / 250$ & 4,8 & 1,0 & \\
\hline Sim & $36 / 437$ & 8,2 & $\begin{array}{c}1,8 \\
(0,9 ; 3,5)\end{array}$ & 0,089 \\
\hline
\end{tabular}

a $\mathrm{O}$ denominador reflete o número de usuários que responderam a questão

UDI: Usuário de droga injetável

DST: Doença sexualmente transmissível

no período do estudo. Por outro lado, tendo em vista a escassez de informações epidemiológicas sobre essa infecção em UD nos municípios estudados, nossos resultados compõem uma situação de base para elaboração de políticas e estratégias de redução de risco e danos relacionados ao uso de drogas ilícitas.

A prevalência da infecção pelo HCV encontrada (6,9\%, IC 95\%: 5,2;9,2) foi superior à verificada em doadores de sangue não-usuários de drogas (1,4\%, Martins et al, ${ }^{17}$ 1994) na mesma região. Por outro lado, considerando estudos em usuários de drogas ilícitas no Brasil, a prevalência aqui estimada foi semelhante às reportadas por Bastos et al ${ }^{2}$ (2000) no município do Rio de Janeiro (5,8\%, IC 95\%: 1,$7 ; 7,1)$ e por Carvalho et $\mathrm{al}^{7}(2003)$ no município de São Paulo (6\%, IC 95\%: 2,2;14,1). Entretanto, foi inferior às verificadas nos municípios de Porto Alegre (25\%; IC 95\%: 15,1;38,1), Belém 
Tabela 3. Análise multivariada dos fatores de risco associados à infecção pelo vírus da hepatite $\mathrm{C}$ em usuários de drogas ilícitas. Goiânia (GO) e Campo Grande (MS), 2005-2006.

\begin{tabular}{|c|c|c|c|}
\hline \multirow{2}{*}{ Fatores de risco } & \multicolumn{2}{|c|}{ Estimativa de risco (IC 95\%) } & $\mathrm{p}$ \\
\hline & Não ajustada & Ajustada ${ }^{\mathbf{a}}$ & \\
\hline
\end{tabular}

Idade (anos)

$\leq 30$

1,0

1,0

$>30$

$25,3(8,9 ; 71,3) \quad 16,0(3,9 ; 66,0) \quad 0,000$

Estado civil

$\begin{array}{lccc}\begin{array}{l}\text { Solteiro } \\ \text { Casado/ } \\ \text { amasiado }\end{array} & 1,0 & 1,0 & \\ \begin{array}{l}\text { Separado/ } \\ \text { viúvo }\end{array} & 2,5(1,2 ; 5,1) & 1,5(0,5 ; 3,9) & 0,436 \\ & 3,1,3 ; 7,2) & 0,4(0,1 ; 1,4) & 0,172\end{array}$

Escolaridade

(anos)

$\begin{array}{lccc}\leq 8 & 1,0 & 1,0 & \\ 9-12 & 1,9(0,9 ; 3,6) & 1,2(0,2 ; 6,6) & 0,862 \\ >12 & 2,3(0,6 ; 7,7) & 0,7(0,1 ; 4,1) & 0,670\end{array}$

Renda familiar

(salário mínimos)

$\begin{array}{lccc}\leq 1 & 1,0 & 1,0 & \\ 2 \text { a } 5 & 1,3(0,6 ; 2,7) & 0,5(0,1 ; 1,5) & 0,205 \\ \geq 5 & 2,7(1,0 ; 6,8) & 0,3(0,8 ; 1,3) & 0,117\end{array}$

Via de uso de drogas

$\begin{array}{lccc}\text { Não injetável } & 1,0 & 1,0 \\ \text { Injetável } & 16,4(8,5 ; 31,3) & 18,0(6,9 ; 47,1) & 0,000\end{array}$

Tempo de uso de drogas (anos)

$\begin{array}{cccc}\leq 10 & 1,0 & 1,0 & \\ >10 & 9,1(3,5 ; 23,2) & 1,6(0,4 ; 5,9) & 0,468\end{array}$

História de transfusão

$\begin{array}{lccc}\text { Não } & 1,0 & 1,0 \\ \text { Sim } & 5,2(2,6 ; 10,4) & 3,1(1,0 ; 9,9) & 0,056\end{array}$

História de cirurgia

$\begin{array}{lccc}\text { Não } & 1,0 & 1,0 & \\ \text { Sim } & 2,0(1,1 ; 3,7) & 1,0(0,4 ; 2,5) & 0,939 \\ \text { Parceiros sexuais } & & & \\ \leq 10 & 1,0 & 1,0 & \\ >10 & 1,7(0,9 ; 3,2) & 2,0(0,8 ; 4,7) & 0,130\end{array}$

Parceiro UDI

$\begin{array}{lccc}\text { Não } & 1,0 & 1,0 & \\ \text { Sim } & 3,1(1,6 ; 6,0) & 0,6(0,2 ; 1,8) & 0,374 \\ \text { istória de DST } & & & \\ \text { Não } & 1,0 & 1,0 & \\ \text { Sim } & 4,2(2,3 ; 7,7) & 1,2(0,5 ; 2,8) & 0,673\end{array}$

Antecedente de prisão

\begin{tabular}{lccc} 
Não & 1,0 & 1,0 \\
Sim & $1,8(0,9 ; 3,5)$ & $1,8(0,7 ; 4,7)$ & 0,229 \\
\hline
\end{tabular}

a Estimativa de risco ajustada por idade, sexo, estado civil, escolaridade, renda familiar, tempo e via de uso de droga, história de transfusão e de cirurgia, número de parceiros sexuais, parceiro usuário de droga injetável (UDI), história de doença sexualmente transmissível (DST) e antecedente de prisão.
(16\%, IC 95\%: 11,3;2,0) e Santos (36,2\%, IC 95\%: 31,9;40,4). ${ }^{10,19,23}$ Essa diferença pode ser explicada pela maior participação de usuários de drogas injetáveis nas populações desses últimos estudos em relação aos primeiros (22\%-27\% versus 10\%-15\%).

A pesquisa do RNA-HCV identifica indivíduos portadores do vírus, principalmente em grupos de elevado risco, como os usuários de drogas. No presente estudo, dos 48 indivíduos anti-HCV reagentes, 41 foram RNA-HCV positivos, resultando em um elevado índice de viremia $(85,4 \%)$. Este fato caracteriza os usuários de drogas como importantes portadores e potenciais disseminadores do $\mathrm{HCV}$, resultado similar a outros estudos. ${ }^{10,13}$

Todas as 41 amostras RNA-HCV positivas foram genotipadas pelo LiPA, sendo o genótipo 1 predominante, seguido pelo genótipo 3 . Resultados semelhantes foram verificados em UDI no município do Rio de Janeiro, ${ }^{20}$ sendo os mesmos prevalentes no Brasil, ${ }^{5}$ bem como na região Centro-Oeste. ${ }^{18}$ Em relação aos subtipos, observou-se maior freqüência de 1a $(63,4 \%)$, seguido de 3a $(19,5 \%)$ e $1 b(17,1 \%)$. A região 5' NC, por ser a mais conservada do genoma viral, permitiu a amplificação pela PCR de um maior número de amostras genotipadas. Por essa razão, a região 5' NC é bastante utilizada na deteç̧ão e genotipagem do HCV, principalmente na prática clínica para definição do esquema terapêutico da hepatite C. ${ }^{9}$

Uma distribuição semelhante foi verificada para os subtipos 1a, 3a e 1b pela análise filogenética da região NS5B (68\%, 20\% e 12\%, respectivamente). Não há, portanto, discordância entre os genótipos e subtipos das 25 amostras caracterizadas pelos dois métodos. Apesar de ambos serem considerados eficientes para determinar principalmente genótipos, resultados discrepantes entre os subtipos do HCV têm sido reportados em outros estudos. Para alguns autores, ${ }^{9,15,22}$ a região NS5B é mais apropriada para subtipagem que a região 5' NC, a qual é muito conservada para diferenciar alguns subtipos, principalmente 1a e 1b. Assim, a análise filogenética da região NS5B, mais indicada para caracterizar o HCV em estudos epidemiológicos, foi utilizada para confirmar os genótipos e subtipos desse vírus na população estudada.

No presente estudo, a idade superior a 30 anos mostrou-se associada à infecção pelo HCV $(\mathrm{OR}=16,0$; IC 95\%: 3,9;66,0), o que é concordante com outras investigações realizadas em usuários de drogas ilícitas. ${ }^{12,16,21}$ Tal associação pode ser explicada pelo risco maior de exposição ao vírus ao longo da vida.

Os indivíduos UDI apresentaram mais chance de infecção pelo HCV (OR= 18,0, IC 95\%: 6,9;47,1) quando comparados aos UDNI. Além disso, a prevalência dessa infecção foi quase 12 vezes maior no primeiro grupo em relação ao segundo (31,4\% versus 
2,7\%, Tabela 2). O risco elevado para hepatite $\mathrm{C}$ por UDI comparado aos UDNI também foi observado por vários autores, ${ }^{2,7,10,13,23}$ o que corrobora a eficiente transmissão desse vírus por via parenteral.

Verificou-se uma tendência à associação entre história de transfusão sanguínea e infecção pelo HCV. Tal associação tem sido reportada, principalmente, quando esse procedimento foi realizado antes da implantação da triagem para anti-HCV nos bancos de sangue em novembro de 1993 no Brasil. ${ }^{4,6}$ De fato, no presente estudo, dentre os 14 indivíduos anti-HCV positivos que receberam transfusão sangüínea, a maioria dessas transfusões foi anterior a essa data (dados não mostrados), ratificando a importância da triagem para anti-HCV nos bancos de sangue no País.

A infecção pelo $\mathrm{HCV}$ se mostrou ainda associada à presença do anti-HBc $\left(\chi^{2}=20,2 ; \mathrm{p}<0,05\right.$; dados não mostrados), considerado marcador de exposição ao HBV. Esse achado, com provável importância clínica e epidemiológica, corrobora os encontrados por outros

\section{REFERÊNCIAS}

1. Alter MJ. Epidemiology of viral hepatitis $C$ infection. World J Gastroenterol. 2007;13(17):2436-41.

2. Bastos FI, Lowndes CM, Castelo-Branco LR, Linharesde-Carvalho MI, Oeleman W, Bernier F, et al. Sexual behaviour and infection rates for HIV, blood-borne and sexually transmitted infections among patients attending drug treatment centres in Rio de Janeiro, Brazil. Int J STD AIDS. 2000;11(6):383-92. DOI: 10.1258/0956462001916100

3. Blackard JT, Shata MT, Shire NJ, Sherman KE. Acute hepatitis $\mathrm{C}$ virus infection: a chronic problem. Hepatology. 2008;47(1):321-31. DOI: 10.1002/ hep. 21902

4. Botelho SM, Ferreira RC, Reis NR, Kozlowski AG, Carneiro MA, Teles SA, et al. E pidemiological aspects of hepatitis $C$ virus infection among renal transplant recipients in Central Brazil. Mem Inst Oswaldo Cruz. 2008;103(5):472-6. DOI: 10.1590/S007402762008000500011

5. Campiotto S, Pinho JRR, Carrilho FJ, Da Silva LC, Souto FJD, Spinelli V, et al. Geographic distribution of hepatitis C virus genotypes in Brazil. Braz / Med Biol Res. 2005;38(1):41-9. DOI: 10.1590/S0100879X2005000100007

6. Carneiro MA, Teles SA, Lampe E, Espírito-Santo MP, Gouveia-Oliveira R, Reis NR, et al. Molecular and epidemiological study on nosocomial transmission of $\mathrm{HCV}$ in hemodialysis patients in Brazil. J Med Virol. 2007;79(9):1325-33. DOI: 10.1002/jmv.20932

7. Carvalho HB, Seibel SD, Burattini MN, Massad E, Reingold A. Vulnerabilidade às infecções pelo HIV, hepatites B e C e sífilis entre adolescentes infratores institucionalizados na cidade de São Paulo, Brasil. J Bras Doenças Sex Transm. 2003;15(3):41-5.

8. Des Jarlais DC, Perlis TE, Stimson GV, Poznyak V; autores também em usuários de drogas, ${ }^{21,23}$ sugerindo a ocorrência de formas comuns de transmissão dos vírus das hepatites B e C em UD.

Em conclusão, o presente estudo mostrou uma prevalência elevada da infecção e do subtipo 1a do HCV em usuários de drogas ilícitas, além do uso injetável de drogas como principal fator de risco para essa infecção. Esses dados, associados à evolução da infecção para cronicidade, à baixa resposta do genótipo 1 à terapia antiviral e a indisponibilidade de uma vacina contra hepatite $\mathrm{C}$ até o momento reforçam a necessidade de programas efetivos de prevenção e controle da hepatite C em usuários de drogas ilícitas.

\section{AGRADECIMENTO}

À Renata Carneiro Ferreira, doutoranda no Instituto de Patologia Tropical e Saúde Pública da Universidade Federal de Goiás, pelo apoio na realização das entrevistas e ensaios sorológicos.
WHO Phase II Drug Injection Collaborative Study Group. Using standardized methods for research on HIV and injecting drug use in developing/transitional countries: case study from the WHO Drug Injection Study Phase II. BMC Public Health. 2006;6:54. DOI: 10.1186/1471-2458-6-54

9. Espírito-Santo MP, Carneiro MAS, Reis NRS, Kozlowski AG, Teles SA, Lampe E, et al. Genotyping hepatitis C virus from hemodialysis patients in Central Brazil by line probe assay and sequence analysis. Braz J Med Biol Res. 2007;40(4):545-50. DOI: 10.1590/S0100879X2007000400013

10. Galperim B, Cheinquer H, Stein A, Fonseca A, Lunge $\mathrm{V}$, Ikuta N. Intranasal cocaine use does not appear to be an independent risk factor for HCV infection. Addiction. 2004;99(8):973-7. DOI: 10.1111/j.13600443.2004.00761.x

11. Ginabreda MGP, Yoshida CFT, Niel C. Genomic characterization of Brazilian hepatitis $C$ virus genotypes 1a and 1b. Braz / Med Biol Res. 1997;30(3):339-45. DOI: 10.1590/S0100879X1997000300006

12. Howe CJ, Fuller CM, Ompad DC, Galea S, Klobin B, Thomas D, et al. Association of sex, hygiene and drug equipment sharing with hepatitis $C$ virus infection among non-injecting drug users in New York City. Drug Alcohol Depend. 2005;79(3):389-95. DOI: 10.1016/j. drugalcdep.2005.03.004

13. Jittiwutikarn J, Thongsawat S, Suriyanon V, Maneekarn $\mathrm{N}$, Celentano D, Razak MH, et al. Hepatitis C infection among drug users in northern Thailand. Am J Trop Med Hyg. 2006;74(6):1111-6.

14. Kumar S, Tamura K, Jakobsen IB, Nei M. MEGA2: molecular evolutionarygenetics analysis software. Bioinformatics. 2001;17(12):1244-5. DOI: 10.1093/ bioinformatics/17.12.1244 
15. Laperche S, Lunel F, Izopet J, Alain S, Dény P, Duverlie $\mathrm{G}$, et al. Comparison of hepatitis C virus NS5b and 5' noncoding gene sequencing methods in a multicenter study. J Clin Microbiol. 2005;43(2):733-9. DOI: 10.1128/JCM.43.2.733-739.2005

16. Macías J, Palacios RB, Claro E, Vargas J, Vergara S, Mira JA, et al. High prevalence of hepatitis $C$ virus infection among noninjecting drug users: association with sharing the inhalation implements of crack. Liver Int. 2008;26:781-6.

17. Martins RBM, Vanderborght BOM, Rouzere CD, Santana CL, Santos CO, Mori DN, et al. Anti-HCV related to HCV PCR and risk factors analysis in a blood donor population of Central Brazil. Rev Inst Med Trop São Paulo. 1994;36(6):501-6. DOI: 10.1590/S003646651994000600005

18. Martins RBM, Teles SA, Freitas NR, Motta-Castro ARC, Souto FJD, Mussi A, et al. Distribution of hepatitis $C$ virus genotypes among blood donors from mid-west region of Brazil. Rev Inst Med Trop São Paulo. 2006;48(1):53-5. DOI: 10.1590/S003646652006000100012

19. Monteiro MR, do Nascimento MM, Passos AD, Figueiredo JF. Hepatite C: prevalência e fatores de risco entre portadores do VIH/SIDA em Belém, Pará, na Amazônia brasileira. Rev Soc Bras Med Trop. 2004;37(Supl 2):40-6.

20. Oliveira MLA, Bastos FI, Telles PR, Hacker MA, Oliveira SAN, Miguel JC, Yoshida CFT. Epidemiological and genetic analyses of hepatitis $\mathrm{C}$ virus transmission among young/short- and long-term injecting drug users from Rio de Janeiro, Brazil. J Clin Virol. 2009;44(3):200-6. DOI: 10.1016/j.jcv.2008.12.008

21. Quaglio G, Lugoboni F, Pajusco B, Sarti M, Talamini $\mathrm{G}$, Lechi A, et al. Factors associated with hepatitis $C$ virus infection in injection and noninjection drug users in Italy. Clin Infect Dis. 2003;37(1):33-40. DOI: $10.1086 / 375566$

22. Sandres-Sauné K, Deny $P$, Pasquier $C$, Thibaut $V$, Duverlie G, Izopet J. Determining hepatitis $C$ genotype by analyzing the sequence of the NS5B region. I Virol Methods. 2003;109(2):187-93. DOI: 10.1016/S01660934(03)00070-3

23. Segurado AC, Braga P, Etzel A, Cardoso MRA. Hepatitis $C$ virus coinfection in a cohort of HIV-infected individuals from Santos, Brazil: Seroprevalence and associated factors. AIDS Patient Care STDS. 2004;18(3):135-43. DOI: 10.1089/108729104322994829

24. Simmonds P, Bukh J, Combet C, Deléage G, Enomoto $\mathrm{N}$, Feinstone $\mathrm{S}$, et al. Consensus proposals for a unified system of nomenclature of hepatitis $C$ virus genotypes. Hepatology. 2005;42(4):962-73. DOI: 10.1002/ hep. 20819

25. Thompson JD, Gibson TJ, Plewniak F, Jeanmougin F, Higgins DG. The CLUSTAL_X windows interface: Flexible strategies for multiple sequence alignment aided by quality analysis tools. Nucleic Acids Res. 1997;25(24):4876-82. DOI: 10.1093/nar/25.24.4876

Pesquisa financiada pelo Ministério da Saúde e Conselho Nacional de Desenvolvimento Científico e Tecnológico (CNPq Proc. $n^{\circ}$. 402783/2004-2).

Artigo submetido ao processo de julgamento por pares adotado para qualquer outro manuscrito submetido a este periódico, com anonimato garantido entre autores e revisores. Editores e revisores declaram não haver conflito de interesses que pudesse afetar o processo de julgamento do artigo.

Os autores declaram não haver conflito de interesses. 